\title{
Ambiguous roles and potential therapeutic strategies of innate lymphoid cells in different types of tumor (Review)
}

\author{
SHIJIE WANG, PIN WU, YONGYUAN CHEN and YING CHAI \\ Department of Thoracic Surgery, The Second Affiliated Hospital, College of Medicine, \\ Zhejiang University, Hangzhou, Zhejiang 310009, P.R. China
}

Received September 11, 2019; Accepted April 7, 2020

DOI: $10.3892 /$ ol.2020.11736

\begin{abstract}
Recent years have witnessed a significant development in the current understanding of innate lymphoid cells (ILCs) and their roles in the innate immune system, where they regulate tissue homeostasis, inflammation, as well as tumor surveillance and tumorigenesis. Based on the limited studies of ILCs in cancer, ILCs may be classified into three subgroups depending on their phenotypic and functional characteristics: Group 1 ILCs, which include natural killer cells and ILC1s; Group 2 ILCs, which only contain ILC2s and Group 3 ILCs, which comprise of LTi cells and ILC3s. Group 1 ILCs predominantly exert antitumor activities, while Group 2 ILCs and Group 3 ILCs are predominantly procarcinogenic in nature. In different types of tumor, each ILC subset behaves differently. Current research is focused on investigating how ILCs may be manipulated and employed as therapeutic strategies for the treatment of cancer. The present review aimed to summarize the characteristics and effects of ILCs in the context of tumor immunology, and provide novel insight into the pro- or anti-tumor activities of ILCs in different types of malignancy, including solid tumors, such as those in the gastrointestinal tract, lung, breast, bladder or prostate, as well as melanoma, further to hematological malignancies, with the aim to highlight potential therapeutic targets for the treatment of cancer.
\end{abstract}

\section{Contents}

1. Introduction

2. Immunoregulatory functions of ILCs

Correspondence to: Professor Ying Chai, Department of Thoracic Surgery, The Second Affiliated Hospital, College of Medicine, Zhejiang University, 88 Jiefang Road, Hangzhou, Zhejiang 310009, P.R. China

E-mail: chaiy@zju.edu.cn

Key words: innate lymphoid cells, neoplasms, plasticity, heterogeneity, anti-tumor activity, cancer immunotherapy
3. ILC subsets demonstrate different behavioral characteristics in different types of tumor

4. ILC plasticity is widespread

5. Therapeutic potential of ILCs as anti-tumor agents

6. Conclusion

\section{Introduction}

The innate and adaptive immune systems of cells, tissues and organs interact with each other to defend against infections and other illnesses and maintain tissue homeostasis $(1,2)$. Over the past few years, increased research on the function of innate lymphoid cells (ILCs) has identified them as being involved in the innate immune system (3-6).

ILCs are defined by three major characteristics: i) Lymphoid morphology; ii) lack of recombination-activating gene (RAG)-dependent rearranged antigen receptors; and iii) absence of myeloid and dendritic cell (DC) phenotypical markers (7). It has been suggested that ILCs are derived from common lymphoid progenitors (CLPs) through downstream cells, natural killer (NK) cell precursors and common helper innate lymphoid progenitors (ChILP). CLPs also have the capacity to give rise to T-cell and B-cell precursors (6). Therefore, ILC development involves a lineage restriction stage, in which $\mathrm{T}$ - and B-cell differentiation potentials are lost through the coordinated expression of specific transcriptional repressors, including inhibitor of DNA binding 2 (Id2) and GATA-binding protein 3 (GATA3) and decreases in the expression of EBF transcription factor 1, SL3-3 enhancer factor 2, E2A immunoglobulin enhancer-binding factor E12/E47 and HEB; this facilitates the potential to differentiate into ILCs. In addition, nuclear factor interleukin-3, T-box expressed in T cells (T-bet), RAR-related orphan receptor- $\gamma \mathrm{t}$ $(\mathrm{ROR} \gamma \mathrm{t})$ and eomesodermin (EOMES) serve roles in ILC lineage development and differentiation.

The first ILCs identified in 1975 by Kiessling et al $(8,9)$ were the NK cells; the name 'killer cell' is derived from their cytotoxic activities, which complement cytotoxic $\mathrm{T}$ cells in killing stressed and transformed cells. Decades later in 1997, lymphoid tissue inducer (LTi) cells were discovered by Mebius et al (10). This subset of $\mathrm{CD}^{+}{ }^{+} \mathrm{CD} 3^{-}$fetal lymphoid cells are essential for the development of Peyer's patches and lymph nodes during embryogenesis and may differentiate into 
NK cells, follicular cells and antigen-presenting cells, but not $\mathrm{B}$ or $\mathrm{T}$ lymphocytes. Within the last decade, the number of identified innate lymphoid cells has significantly expanded due to the contributions of several laboratories that worked to characterize previously unknown subtypes of cells of hematopoietic origin. For instance, an LTi-like cell population located in mucosa-associated lymphoid tissues, which provides an innate source of interleukin (IL)-22 that contributes to mucosal hemostasis, were named NK22 cells by Cella et al (11). Lineage T1/ST2 (IL1RL1, a subunit of IL33R) ${ }^{+}$IL-17 receptor $\mathrm{B}^{+}$cells, known as 'Nuocytes', FALC Lineage-c-Kit ${ }^{+} \mathrm{Sca}-1^{+}$ cells, named 'natural helper cells' and gut-associated Lineage ${ }^{-S c a}-1^{+} \mathrm{Kit}^{\text {int }}$ cells, termed 'MPP ${ }^{\text {type } 2}$ cells' have all been categorized as type 2 T-helper cell (Th2)-type innate lymphoid subsets that may expand in pro-allergic immunity, respond to helminth infections and induce the initiation of asthma (12-16). IFN- $\gamma$-producing non-cytotoxic NK-like cells have also reportedly been isolated from the gastrointestinal epithelium (17).

To standardize the terminology of ILCs, it was suggested that all non-typical lymphocytes should be grouped into one family termed innate lymphoid cells (ILCs). Within this family, the ILCs were subsequently categorized into three groups (groups 1-3) based on their expression levels of master regulatory transcription factors and the secretion of different cytokines, which are strikingly similar to the cytokine-producing profiles of $\mathrm{CD}^{+} \mathrm{T}$ cell subtypes (Th1, Th2 and Th17) (18). Furthermore, it has since been proposed by Vivier et al (19) that the classification of ILCs should include five subsets: NK cells, ILC1s, ILC2s, ILC3s and LTi cells, which has now been approved by the International Union of Immunological Societies (19). Group 1 ILCs include NK cells and ILC1s; both cell types produce interferon (IFN) $-\gamma$ and rely on the transcription factor T-bet for their differentiation, despite the differences observed in their developmental pathways; NK cells are generated from NK precursors, whereas ILC1s are derived from ChILP. Group 2 ILCs only contain the single subset, ILC2s, which secrete IL-4, IL-5, IL-13 and amphiregulin, and express B-cell lymphoma/leukaemia 11B, growth factor-independent 1 and GATA3. Finally, the group 3 ILC subset, which comprises LTi and ILC3s, produce IL-22 and/or IL-17 and use ROR $\gamma \mathrm{t}$ and aryl hydrocarbon receptor (AhR) for their growth and function (Fig. 1).

It is a well-established fact that the immune system is involved in the suppression of cancer initiation and development. Numerous studies have focused on the interaction between immune cells and the tumor microenvironment; for instance, NK cells have been observed to serve a critical role in immune surveillance and eliciting a response to various types of tumor through expressing a large number of immune recognition receptors (NK receptors), as well as secreting perforin, granzyme and IFN- $\gamma$. However, despite the role of NK cells in cancer having been investigated extensively and reviewed elsewhere $(20,21)$, the function of other ILCs in tumor immunity remains largely elusive. The present review aimed to provide an overview of the number and function of ILCs other than NK cells in different types of cancer, both human and murine, as well as their plasticity, which may affect their role in tumor immunity.

\section{Immunoregulatory functions of ILCs}

As a distinct family of innate lymphocytes, ILCs have specific functions in immunity (22). These lymphocytes do not possess RAG-dependent rearranged antigen receptors but rather respond rapidly toward environmental challenges. Unlike NK cells, most subsets of helper-type ILCs (ILC1s, ILC2s, ILC3 and LTi cells) are tissue-resident; they reside in selected tissues and organs where they remain ready for rapid responses. Of note, ILC1s are enriched in the salivary glands, liver, small intestine, uterus and adipose tissue and ILC2s are the major population of ILCs in the skin and lung, while ILC3s and LTi are abundant in the gut and mesenteric lymph nodes (23).

ILCs act as a double-edged sword in immunity. The same subset of ILCs that inhibit infections and promote tissue-protective responses may produce pathogenetic effects during chronic activation of inflammation. ILC1s are essential in barrier defense; they cooperate with Th1 cells against microbial pathogens including bacteria or parasites $(17,24)$. However, in the inflamed intestine of patients with Crohn's disease, the frequency of ILC1s is much higher compared with that in normal tissue, highlighting the pathological role for ILC1s in gut mucosal inflammation (25). ILC2s are linked to pro-allergic and anti-parasitic immunity and promote tissue repair through the production of IL-13 and amphiregulin $(13,26)$. Dysregulation of ILC2 signaling circuitry may accelerate fibrotic responses and promote tumor development (27). ILC3s have an important role in stabilizing the epithelial barrier by protecting epithelial cells from apoptosis and inducing epithelial cells to express anti-microbial peptides through IL-22 production $(28,29)$. However, ILC3s may also be pathogenic when producing IFN- $\gamma$ and/or IL-17 during colitis $(30,31)$. IL-17A ${ }^{+}$ILC3s are associated with obesity-induced airway hyperreactivity (32). LTi cells were originally discovered as key components required for the formation of Peyer's patches and lymph nodes during embryogenesis. They are also involved in tissue repair after infection (33).

Indeed, ILCs perform as mediators of inflammation in various tissues and organs, where they are also responsible for cancer-associated inflammation. While they facilitate an effective host anti-tumor response, they are also likely to promote tumor growth, progression and immunosuppression $(34,35)$. The ambiguous roles of ILCs in cancer depend on their phenotype, the type of cancer and the immune microenvironment surrounding the tumor. In the following, it is discussed how the different ILC subsets behave within tumors and how ILC-associated inflammation modulates the tumor microenvironment and impacts tumorigenesis (Table I).

\section{ILC subsets demonstrate different behavioral characteristics in different types of tumor}

ILCs in digestive system tumors. The liver is rich in ILC1s, which are also referred to as intrahepatic NK cells or tissue-resident NK cells $(24,36)$; however, a previous study observed that the absolute number and immune surveillance function of ILC1s were suppressed in patients with hepatocellular carcinoma (HCC), which in turn contributed to the development and progression of tumors (37). Conversely, 


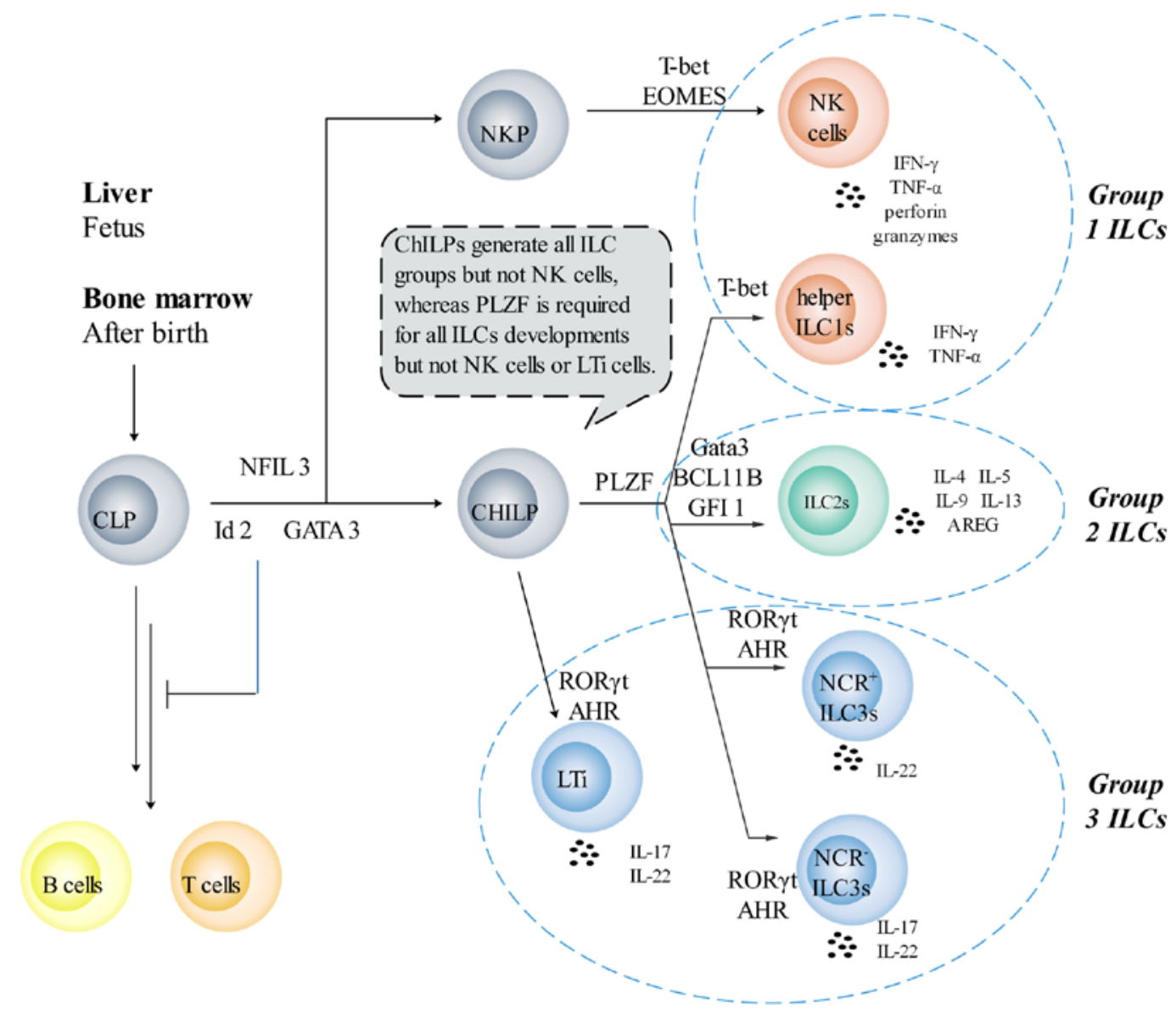

Figure 1. Development, classification and secretion functions of ILCs. ILCs are all derived from CLPs and require Id2 and GATA3 to suppress alternative generation of T and B cells. Mature ILCs are generally divided into 3 groups. Group 1 ILCs include NK cells and helper ILC1s, dependent on T-bet and EOMES for their differentiation. Group 2 ILCs express BCL11B, GFI1 and GATA3 for their differentiation. Group 3 ILCs consist of LTi, NCR- ILC3s and NCR ${ }^{+}$ ILC3s, which employ ROR $\gamma \mathrm{t}$ and AhR for their development. Helper ILC1s, group 2 and 3 ILCs mirror the cytokine-producing profiles of CD4+ Th subtypes (Th1, Th2 and Th17), whereas NK cells may be the counterpart of CD8 ${ }^{+}$cytotoxic T cells and may express perforin and granzymes. ChILP, common helper innate lymphoid progenitors; ILC, innate lymphoid cell; IL, interleukin; TNF, tumor necrosis factor; INF, interferon; NFIL3, nuclear factor interleukin-3; Id2, inhibitor of DNA binding 2; GATA3, GATA-binding protein 3; PLZF, promyelocytic leukemia zinc-finger; BCL11B, B-cell lymphoma/leukaemia 11B; GFI1, growth factor-independent 1; Th, T-helper; T-bet, T-box expressed in T cells; EOMES, eomesodermin; ROR $\gamma$ t, RAR-related orphan receptor- $\gamma$ t; AhR, aryl hydrocarbon receptor; NCR, natural cytotoxicity receptor; NK, natural killer; AREG, amphiregulin; CLPs, common lymphoid progenitors; LTi, lymphoid tissue inducer.

a more recent study suggested that ILC1s were increased in mice with hepatitis B virus-infected hepatocellular carcinoma; ILC1 subtype cells secreted IFN- $\gamma$ to trigger epithelial-mesenchymal transition by suppressing E-cadherin expression through the phosphorylated STAT1 pathway, which also promoted tumorigenesis (38).

Of note, McHedlidze et al (39) demonstrated that the IL-33/IL-13 axis, which is linked to ILC2s, also promoted hepatic fibrosis, whilst another study discovered that the IL-33/ILC2/IL-13 circuit in a murine biliary injury model promoted cholangiocyte hyperplasia, which induced cholangiocarcinoma with liver metastases (40). Thus, these studies suggested the possible roles for ILC2s in liver carcinogenesis (Fig. 2).

Group 3 ILCs may also serve a role in the pathogenesis of liver cancer by producing IL-17, e.g., following the induction by Helicobacter hepaticus, and IL-22 due to STAT3 activation, of which increased expression levels were detected in patients or mice with hepatitis B- or C-associated HCC $(38,41)$; however, why and how ILC3s overproduce IL-17 or IL-22 under HCC conditions remains to be determined.
Inflammatory bowel disease (IBD), including Crohn's disease (CD) and ulcerative colitis, is an important risk factor for the development of colorectal cancer (CRC); IL-23 receptor signaling is associated with the pathogenesis of IBD, which consequently promotes tumor growth in the gut. Geremia et al (42) indicated that in the inflamed intestine of patients with CD, ILC3s accumulated in response to IL-23 and contributed to intestinal inflammation through the secretion of inflammatory factors, principally IL-17, and the recruitment of other lymphocytes. Further studies have reported that the IL-23/IL-23 receptor (IL-23R) ${ }^{+}$ILC3s/IL-17 axis may indirectly initiate and promote gut tumorigenesis through the establishment of a long-term inflammatory process in the gut; however, the mechanisms that link gut inflammation with carcinogenesis remain to be fully elucidated (43-45).

Chan et al (46) suggested that IL-23 may be sufficient to induce the formation of rapid de novo intestinal adenomas in mice through IL-17-producing Thy $1^{+} \mathrm{IL}_{-} 23 \mathrm{R}^{+}$ILC3s, which occurred prior to inflammatory cell infiltration and independently of pre-existing carcinogens. Furthermore, 


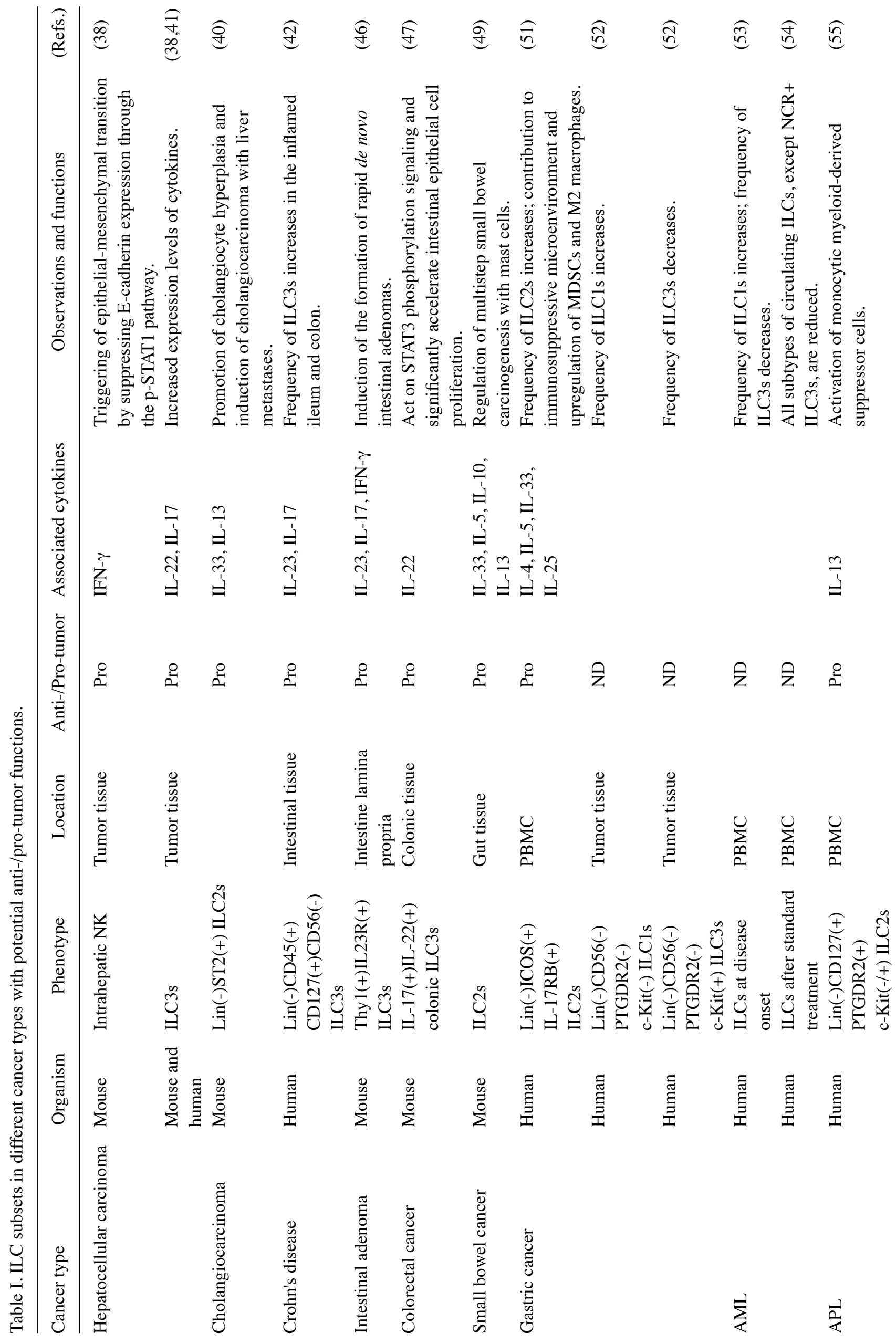




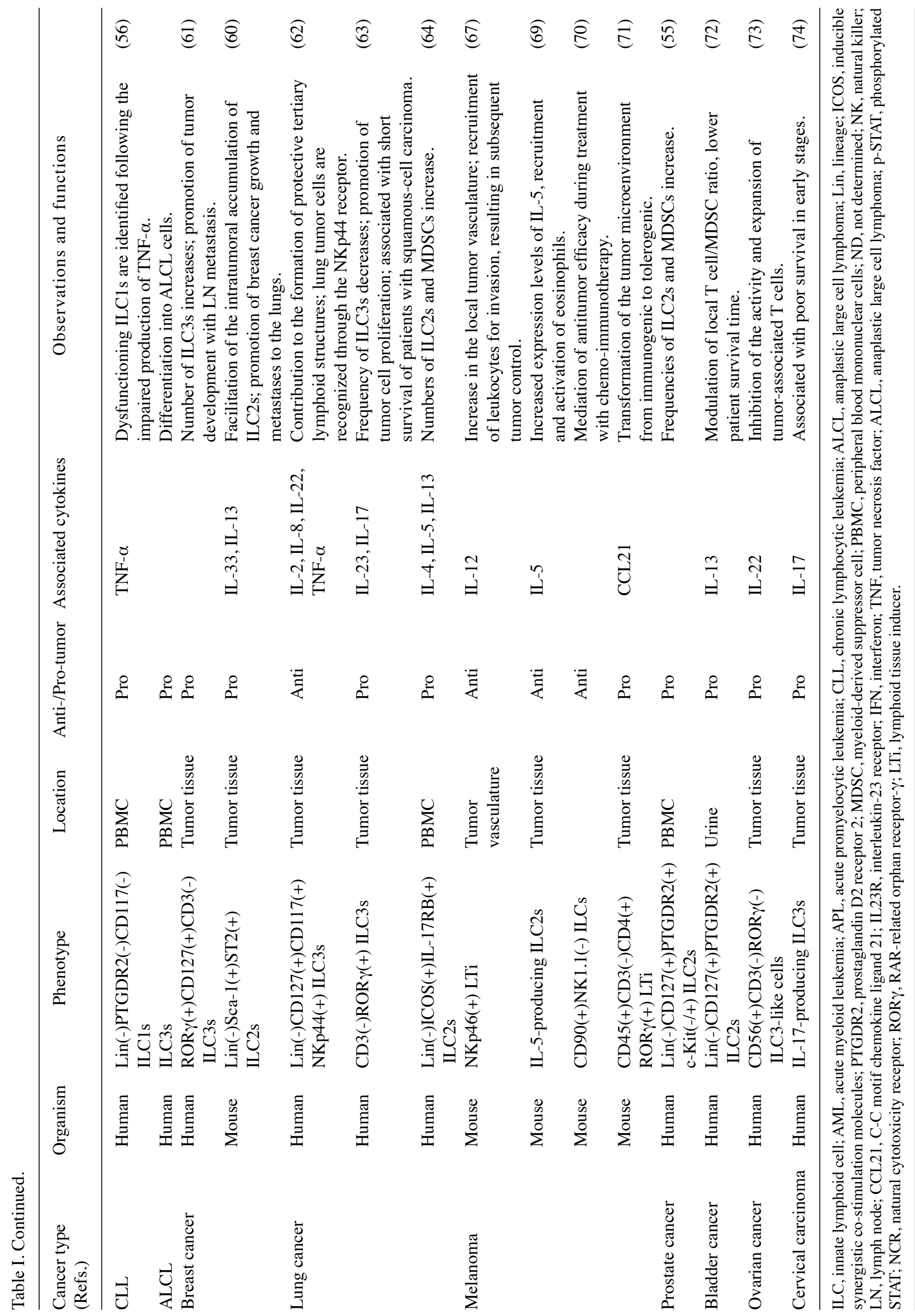




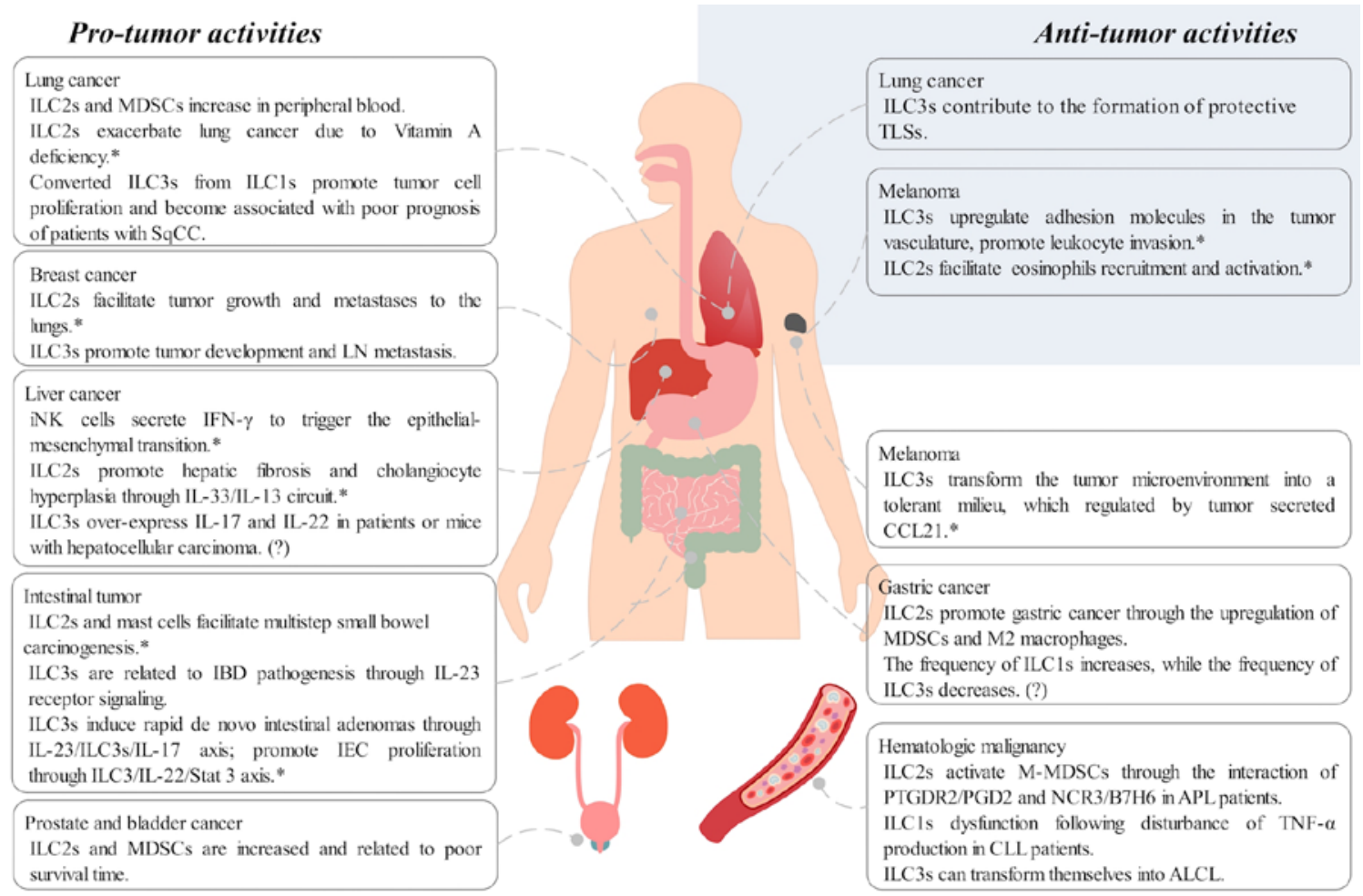

Figure 2. Dysregulation and potential functions of innate lymphoid cells in different cancer types. *Pro- or anti-tumor mechanisms of ILCs only observed in murine models, waiting for further investigations in humans; 'Changes in the proportion or secretion status of ILCs were reported but its role in tumors remains elusive. M-MDSC, monocytic myeloid-derived suppressor cell; SqCC, squamous cell carcinoma; LN, lymph node; ILC, innate lymphoid cell; IL, interleukin; IFN, interferon; IBD, inflammatory bowel disease; IEC, intestinal epithelial cell; TLS, tertiary lymphoid structure; CCL21, C-C motif chemokine ligand 21; PGD2, prostaglandin D2; PTGDR2, prostaglandin D2 receptor 2; TNF, tumor necrosis factor; APL, acute promyelocytic leukemia; CLL, chronic lymphocytic leukemia; ALCL, anaplastic large cell lymphoma.

Kirchberger et al (47) investigated the roles of ILC3-produced IL-22 and indicated that colonic ILC3s promoted CRC through IL-22 secretion, which selectively acted on STAT3 phosphorylation signaling and significantly accelerated intestinal epithelial cell proliferation in a mouse model. The study also revealed that IL-22 expression levels were markedly increased in human CRC tumor tissue compared with those in normal tissue, further highlighting the carcinogenic role of the ILC3/IL-22/STAT3 axis in the human intestinal tract. It was subsequently reported by Bergmann et al (48) that the ILC3/IL-22/STAT3 axis may be, at least in part, regulated by the caspase recruitment domain protein 9 (Card9), a myeloid cell-specific signaling protein, which specifically promoted the ILC3-induced production of IL-22, resulting in the promotion of colitis-associated cancers. More recently, Saadalla et al (49) argued that mast cells (MCs) may promote murine small bowel cancer in two steps: First, overexpression of IL-10 by T cells may contribute to $\mathrm{MC}$ expansion and polypus growth in the small bowel and then a second population of MCs expands during the process of polypus-to-carcinoma transition. In this multistep model of small bowel carcinogenesis, ILC2s have also been observed to be significantly expanding in the diseased region compared with the healthy surrounding tissues, and IL-5 and IL-13 are highly expressed. Thus, it was hypothesized that MCs, group 2 ILCs, as well as type-2 inflammation may coordinate to regulate this multistep process in small bowel carcinogenesis.

Studies on ILCs in patients with gastric cancer are rare; however, the accumulation of cells with Th2 phenotypes was suggested to be associated with gastric cancer and with poor prognosis of affected patients (50). Bie et al (51) analyzed the expression levels of ILC2-associated genes or molecules, including ROR $\alpha$, GATA3, prostaglandin D2 (PGD2) receptor 2 (PTGDR2) and type-2 inflammation factors, in peripheral blood mononuclear cells and determined that they were significantly increased in patients with gastric cancer. A further study using flow cytometry revealed that the frequency of circulating ILC2s was increased in patients with gastric cancer, which may be closely associated with the increased expression levels of myeloid-derived suppressor cells (MDSCs) and M2 macrophages, and contributed to the immunosuppressive microenvironment (51). In gastric cancer, a predominant group 1 ILC phenotype was also detected in the malignant tissues compared with that in para-tumor tissues, whereas group 3 ILC phenotypes were identified in a smaller number of the tumor tissues (52). In conclusion, these studies mainly focused on changes in the proportions of ILCs in gastric cancer; however, whether they are necessary for gastric tumor growth, invasiveness and metastasis, or otherwise inhibit tumor initiation and development remains to be determined.

ILCs in hematological malignancies. Hematological malignancies mainly comprise leukemias and lymphomas. It has been observed that the frequency, subset distribution and function of ILCs in patients with leukemia changes during leukemogenesis and is also influenced by current treatments. In patients with acute myeloid leukemia (AML) at disease 


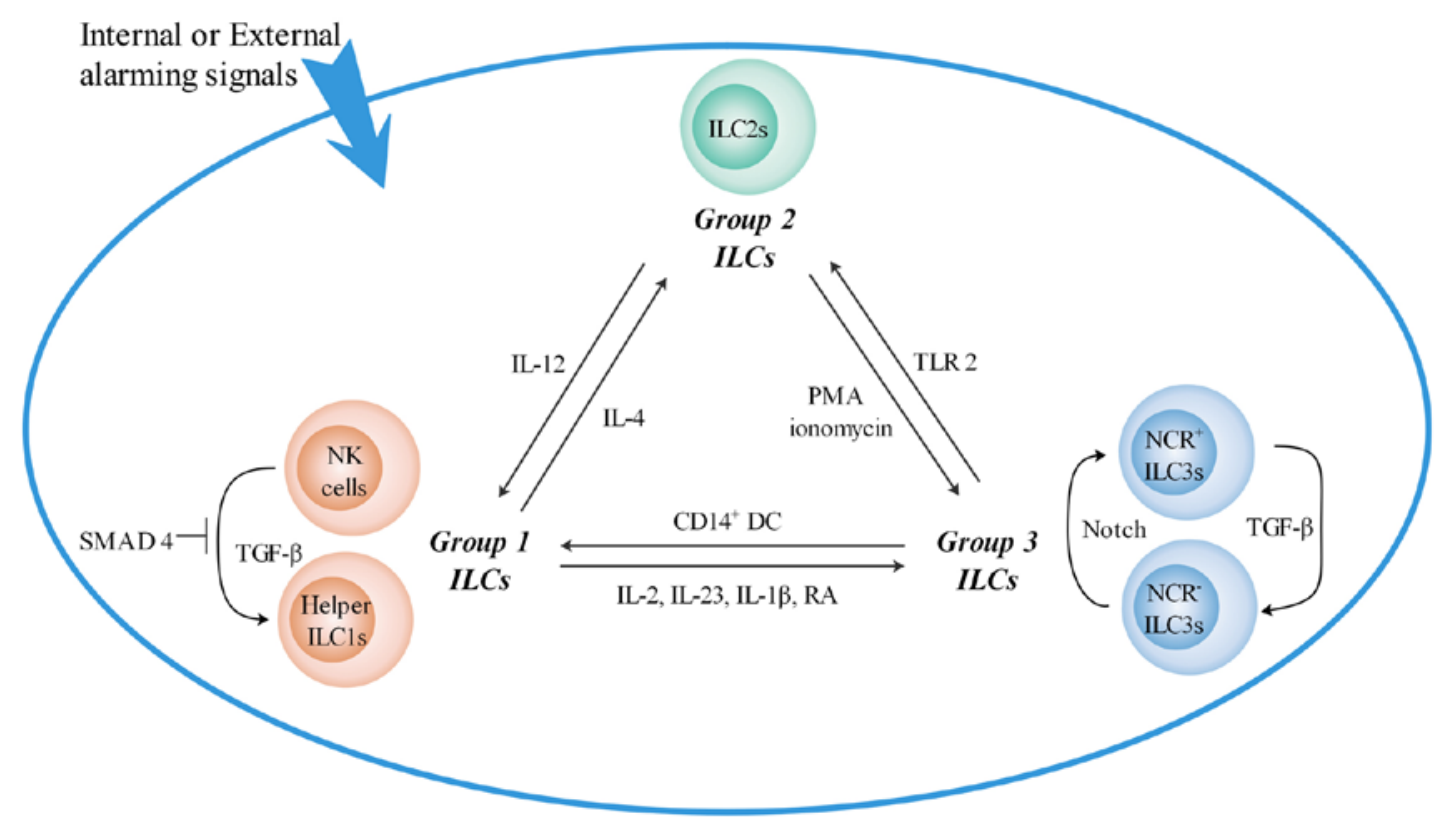

Figure 3. Plasticity of innate lymphoid cells. When exposed to internal or external signals elicited by pathogens, allergens or transformed cells, ILCs may transform their phenotypes. Specifically, helper ILC1s convert to NK cells responding to TGF- $\beta$ yet SMAD4 inhibit the conversion. Notch signaling drives the transformation of NCR- ILC3s to NCR ${ }^{+}$ILC3s and it is reversed by TGF- $\beta$. Group 1 and 2 ILCs convert into each other under the influence of PMA plus ionomycin and TLR2, respectively. ILC2s and ILC3s convert into each other under the influence of IL-12 and IL-4, respectively. Group 1 ILCs convert into Group 3 ILCs in response to IL-2, IL-23, IL-1 $\beta$ and RA, and Group 3 ILCs convert into Group 1 ILCs in response to CD14 ${ }^{+}$DCs, respectively. ILC, innate lymphoid cell; DC, dendritic cell; TLR 2, Toll-like receptor 2; PMA, phorbol 12-myristate 13-acetate; IL, interleukin; TGF, transforming growth factor; NCR, natural cytotoxicity receptor; NK, natural killer; RA, retinoic acid.

onset, ILC1s were significantly increased, whereas ILC3s were significantly reduced. In addition, although no differences were observed in the frequency of ILC2s, the production of cytokines associated with ILC2s was impaired compared with that in healthy donors (53). Furthermore, following two cycles of standard chemotherapy, ILC populations were partially recovered, particularly natural cytotoxicity receptor $(\mathrm{NCR})^{+}$ ILC3s, which were restored to normal levels. Another study by Munneke et al (54) concluded that all subtypes of circulating ILCs, except $\mathrm{NCR}^{+}$ILC3 cells, were significantly reduced in treated patients with AML, who received standard treatment protocols, such as chemotherapy and allogeneic hematopoietic stem cell transplantation, compared with those in healthy donors. Furthermore activated ILCs were reported to have roles in protecting against the development of graft-vs. -host disease (GVHD), possibly by expressing activation, proliferation and tissue homing markers, including CD69, Ki-67, C-C motif chemokine receptor 6 and cutaneous lymphocyte-associated antigen (CLA) (54).

Studies on patients with acute promyelocytic leukemia (APL) have indicated that ILC2s were significantly increased and hyperactivated, and served immunosuppressive roles in tumor occurrence and development. Trabanelli et al (55) suggested that the pro-APL function of ILCs may occur through the PGD2/PTGDR2/natural cytotoxicity-triggering receptor 3 (NCR3)/B7H6/ILC2/IL-13/monocytic (M)-MDSCs axis. Of note, the binding of elevated tumor-derived PGD2 and B7H6 to PTGDR2 and NCR3, respectively, on ILC2s initiated the expansion and hyperactivation of ILC2s in patients with APL. Subsequently, the over-secretion of IL-13 by ILC2s is activated M-MDSCs, which serves an important role in immunosuppression in cancer. Furthermore, blocking any steps of this axis reversed the immunosuppression and significantly prolonged the survival time in humanized leukemic mice, while treating APL with all-trans retinoic acid reversed the increase in ILC2-induced MDSCs, as well as tumor- and ILC2-derived factors, in human patients with APL. Thus, this novel tumor immunosuppressive axis may represent a possible target for the treatment of APL; however, it further investigation is required.

ILCs are also significantly dysregulated in terms of their numbers and function in patients with chronic lymphocytic leukemia (CLL) prior to any treatments. However, unlike AML, the total ILC counts in the peripheral blood were significantly increased compared with those in healthy donors, and a rise in ILCs with disease progression was observed. Furthermore, dysfunctioning ILC1s were observed following disturbance of TNF- $\alpha$ production, which was consistent with what was discovered for NK cells, and may reflect an immunosuppressive effect of malignant cells in patients with CLL (56).

Lymphomas are a heterogeneous group of tumors that involve the malignant transformation and monoclonal proliferation of lymphoid cells in lymphoreticular sites; it is likely that ILCs may atypically differentiate into malignant hematologic cells. In a study by Schleussner et al (57), it was suggested that anaplastic large cell lymphoma (ALCL), a rare type of non-Hodgkin's lymphoma involving aberrant $\mathrm{T}$ cells or null lymphocytes, may originate from ILC3s; ALCL cell lines consistently expressed ILC3-associated genes, including ROR $\gamma \mathrm{t}, \mathrm{AhR}, \mathrm{IL}-22$, IL-26 and IL-23R, whilst there was a lack of $\mathrm{B}$ - or $\mathrm{T}$-cell receptor gene rearrangements.

ILCs in breast cancer. Breast cancer is one of the most common malignant neoplasms, which is associated with a 
significant proportion of cancer-associated mortalities worldwide (58). Certain lymphoid chemokines, including C-X-C motif chemokine ligand 13 (CXCL13) and C-C motif chemokine ligand 21 (59), have been indicated to have important roles in breast tumor metastasis, and the functions of innate cells and associated cytokines in these tumors are currently under investigation. A study by Jovanovic et al (60) indicated that in a 4T1 mouse breast cancer model, endogenous IL-33 was increased in a time-dependent manner during cancer progression, which facilitated the intratumoral accumulation of immunosuppressive IL-13-producing innate lymphoid cells, and in turn, promoted breast cancer growth and metastases to the lungs. Furthermore, in human patients with breast tumors, Irshad et al (61) reported an absolute increase in ILC3s in tumor tissue, which was associated with an increased likelihood of lymph node metastasis.

ILCS in lung cancer. Studies have indicated positive as well as negative roles of ILC3s in lung carcinogenesis. For instance, Carrega et al (62) discovered an anti-tumor function of ILC3s in non-small cell lung cancer (NSCLC); $\mathrm{NCR}^{+}$ILC3s were observed to be accumulated in human NSCLC tissue at the edge of tumor-associated lymphoid aggregates, which may contribute to the formation of protective tertiary lymphoid structures, a certified favorable predictor of tumor outcomes. This immunosurveillance function of ILC3s may contribute to their potential ability to recognize lung tumor cells through the NKp44 receptor. Recently, Koh et al (63) investigated the process of the conversion of ILC1s into ILC3s in squamous cell carcinomas (SqCC) of NSCLC, but not of adenocarcinomas, and observed that it was possibly induced through the production of IL-23 from lung cancer cells. However, these converted ILC3s did not exert any anti-tumor activity as $\mathrm{NCR}^{+} \mathrm{ILC}_{\mathrm{s}} \mathrm{s}$ do, but on the contrary, promoted tumor cell proliferation. Of note, an increased number of ILC3s was indicated to be associated with poor prognosis of patients with $\mathrm{SqCC}$ in that study (63). Furthermore, Wu et al (64) observed significantly increased numbers of ILC2s and MDSCs in the peripheral blood of patients with lung cancer, as well as increases in the expression levels of ILC2-associated transcription factors and cytokines, including IL-4, IL-5 and IL-13, which suggested that ILC2s may have pro-tumor properties in lung cancer. More recently, Cui et al (65) discovered that vitamin A deficiency promoted the infiltration of ILC2s into the lung and exacerbated lung carcinoma in mice. This discovery may provide a simple but effective strategy for the treatment of lung cancer.

ILCs in melanoma. Previous studies have provided an abundance of evidence supporting the potent tumoricidal role of IL-12 through the activating group 1 ILCs, including NK cells (66); however, a study by Eisenring et al (67) reported that IL-12-modulated tumor suppression was linked to NKp46+ $\mathrm{LTi}$ in subcutaneous melanoma, and was completely independent of T cells or NK cells. In the present study, IL-12 triggered tumoricidal immunity through stimulating $\mathrm{NKp} 46^{+} \mathrm{LTi}$ cells, which are dependent on the transcription factor $\operatorname{ROR} \gamma$, and these activated LTi induced increases in the expression levels of adhesion molecules in the local tumor vasculature, recruited leukocytes for invasion to thereby achieve tumor control. Furthermore, Lotfi et al (68) and Ikutani et al (69) reported that
ILC2s had increased expression levels of IL-5 in tumor tissue that resulted in the recruitment and activation of eosinophils, which was linked to an improved prognosis in numerous types of solid tumor. More recently, a subset of NK1.1-negative ILCs was reported to be responsible for the impact of a combined chemotherapy and immunotherapy treatment regimen in a murine B16 melanoma model, highlighting the potential anti-tumor role for ILC2s and/or ILC3s (70). Conversely, in certain cases, LTi-cell recruitment in melanoma was reported to be correlated with the expression of CCL21 in the tumor, which was discovered to be a signal to transform the tumor microenvironment from immunogenic to tolerogenic, which subsequently promoted immune evasion (71). Thus, subsets of ILCs were indicated to be tumoricidal in melanoma.

ILCs in tumors of the genitourinary system. So far, the immunosuppressive roles of the ILC2/MDSC axis in patients with gastric cancer, APL and lung cancer were discussed. Similarly, Trabanelli and Chevalier (55) also discovered an uncommon enrichment of ILC2s and M-MDSCs in prostate cancer. Furthermore, patients with non-muscle-invasive bladder cancer had significantly lower recurrence-free survival when the local T cell/MDSC ratio, which is modulated by ILC2s, was low (72). These results suggest that the ILC2/IL-13/MDSC axis may have a tumor-promoting function and targeting this pathway may be helpful for the treatment of prostate and bladder cancers.

ILCsingynecologicalcancers. The tumorigenesis of gynecologic cancers, including ovarian carcinoma and cervical carcinoma, has also been linked to ILCs. A distinct ILC3s-like population was identified in human high-grade serous carcinoma. These cells highly expressed NKp46 and produced IL-22, but unlike conventional ILC3s, they lacked ROR $\gamma$ t. These ILC3s-like cells are able to inhibit tumor-infiltrating lymphocyte (TIL) expansion and alter TIL cytokine production via NKp46 expression. In consideration of their suppressive capacity, these cells were described as regulatory ILCs (ILCregs). Patients possessing a high level of ILCregs had a reduced immunosurveillance and a shorter recurrence-free survival time (73). Furthermore, in human squamous cervical carcinoma, IL-17-producing ILC3s were also associated with poor survival (74).

\section{ILC plasticity is widespread}

There is an abundance of evidence to suggest that the effector functions of Th cells are modulated by internal or external signals from pathogens, allergens or transformed cells, such as cytokines and other transcription or growth factors $(75,76)$. Of note, even mature post-thymic $\mathrm{CD}^{+}$cells may lose the expression of Th-inducing POZ/Krueppel-like factor, the master regulator of Th cells, and differentiate into functional cytotoxic $\mathrm{T}$ cells in response to infection or other chronic stimulations (77). These results demonstrated the plasticity of $\mathrm{T}$ cells, and in a similar fashion, subtypes of ILCs have also demonstrated plastic properties as conventional $\mathrm{T}$ cells in response to various signals. In the context of malignancies, these plasticities may change the characteristics of ILCs with either anti-tumor or tumor-promoting abilities, which is particularly important to tumor immunity (Fig. 3). 
Using genetically engineered mouse models combined with flow cytometry and global transcriptomic analysis techniques, Gao et al (78) observed the transforming growth factor (TGF)- $\beta$-signaling-dependent conversion of tumoricidal NK cells, defined as CD49a $\mathrm{a}^{-} 49 \mathrm{~b}^{+}$, into ILC1 populations that were unable to control local tumor development and metastasis (defined as $\mathrm{CD} 49 \mathrm{a}^{+} \mathrm{CD} 49 \mathrm{~b}^{-}$) in the tumor microenvironment; this was impeded by the transcription factor SMAD4 by restricting non-canonical signaling through TGF- $\beta$ receptor 1 in NK cells (79). In addition, $\mathrm{NCR}^{+}$ILC3s are mainly derived from NCR ILC3s through the stimulatory expression of transcription factors ROR $\gamma \mathrm{t}$, T-bet and AhR, with Notch signaling potentially also contributing to this plasticity. Chea et al (80) and Viant et al (81) observed that TGF- $\beta$ suppressed the differentiation of $\mathrm{NCR}^{+}$ILC3s from NCR ILC3s. Therefore, the plasticity of ILC3s subsets may be modulated by the balance between the opposing effects of Notch and TGF- $\beta$ signaling.

Several previous studies have reported the plasticity of ILC2s in both human and murine models (82-85). In chronic obstructive pulmonary disease and other respiratory diseases, human ILC2s were directly activated by IL-1 $\beta$, while IL-12 lead to the conversion of these stimulated ILC2s into ILC1s (82); this was confirmed through the phenomenon that patients with Mendelian susceptibility to mycobacterial disease (MSMD) (susceptible to poorly pathogenic mycobacterial species due to the deficiency of IL-12R $\beta 1$ ) failed to generate ILC1s (83). Of note, this conversion was reversed by IL-4 but the impact of IL-4 was confined to ILC2-derived ILC1s, for IL-4 was not able to stimulate intrinsic CD127+ ILC1s and shift them towards an ILC2 phenotype with the expression of the characteristic marker PTGDR2 (82). A study by Bernink et al (86) reported that in the presence of IL-1 $\beta$, IL-2 and IL-23, human CD127 ILC1s were able to differentiate into ILC3s, but not ILC2s, and retinoic acid may enhance this process. By contrast, $\mathrm{CD} 14^{+} \mathrm{DCs}$ promoted the differentiation of ILC3s into CD127+ ILC1s in the diseased tissues of patients with CD. Furthermore, Toll-like receptor 2 signaling was discovered to promote the expression of IL-5, IL-13 and IL-22 in human CD127 ${ }^{+}$LTi-like innate cells, while IL-25-responsive inflammatory ILC2 populations in lung tissue expressed ROR $\gamma \mathrm{t}$ and produced IL-17 upon stimulation with phorbol 12-myristate 13-acetate plus ionomycin. This indicated that group 2 and group 3 ILCs may be able to convert into each other $(87,88)$.

\section{Therapeutic potential of ILCs as anti-tumor agents}

Over the past few decades, surgery, radiotherapy and chemotherapy have been the mainstay of cancer treatment. Given the vital roles of immune cells in shaping the tumor microenvironment and the initiation and metastasis of tumors, immunotherapy has increasingly demonstrated strong efficacy as a novel treatment option. As for ILCs, the anti-tumor activities of NK cells have been well demonstrated in various types of tumor $(20,89)$, whereas the potential clinical use of other non-cytotoxic ILCs, such as ILC1s, ILC2s and ILC3s, as anti-tumor reagents has remained relatively unacknowledged.

Blockade of the programmed cell death protein 1 (PD-1), cytotoxic T lymphocyte-associated protein 4 (CTLA-4) and other immune checkpoints are proving to be effective cancer immunotherapies for subsets of patients with various types of tumor $(90,91)$. Inhibitory antibodies against: CTLA-4 (such as ipilimumab for the treatment of melanoma), PD-1 (such as pembrolizumab for the treatment of melanoma and NSCLC, and nivolumab for the treatment of melanoma) and PD-1 ligand 1 (PD-L1) (such as atezolizumab for the treatment of NSCLC and urothelial tumors, and avelumab for the treatment of Merkel cell carcinoma) are called immune checkpoint blockade (ICB) molecules, and have been approved by the Food and Drug Administration (FDA) of the United States and since used widely in the clinic with good efficacy (92). Studies have demonstrated that PD-1 and CTLA- 4 are also expressed on activated ILCs, particularly in the tumor environment (93). Within malignant breast tissues, PD-1 was highly expressed on ILC2s, whereas CTLA-4 expression was detected to be uniformly upregulated in ILC1s and ILC2s. In gastrointestinal tumor tissues, a significant increase in PD-1 expression levels was observed on ILC2s (52). In addition, Tumino et al (94) reported that ILC3s in malignant pleural effusions (PE) taken from metastatic cancers overexpressed functional PD-1, whereas malignant PE-derived tumor cells simultaneously expressed PD-L1, suggesting the immune function of ILC3s in malignancies, which may be hindered by the PD-1/PD-L1 interaction. However, ICB treatment also has side effects, with one of the most familiar toxicities being ICB-associated colitis. Of note, the severity of ICB-associated colitis was indicated to be associated with an increased number of ILC $3 \mathrm{~s}$ in the intestinal mucosa, and colitis was therapeutically prevented following the reduction in the number of ILC3s (95). This phenomenon may guide studies addressing the immune-associated adverse effects of ICB treatment.

ILC1s have anti-tumor as well as pro-tumor activities. The tumoricidal function of ILC1s may be attributed to the expression of TRAIL, a member of the TNF family that exerts its anti-tumor activity through the apoptotic pathway. Turchinovich et al (96) discovered that the expression of TRAIL on the cell surface of ILC1s may be modulated by NKp46, which is more commonly known as the activating receptor that triggers the release of cytotoxic factors by NK cells, and the marker expressed by other helper ILCs. In this regard, the NKp46-dependent TRAIL pathway may be a potential target for cancer treatment.

Group 2 and group 3 ILCs are mostly considered to be pro-carcinogenic ILC subtypes, as the type 2 and type 3 cytokines that they create are demonstrated to be highly associated with promoting tumor growth and blocking anti-tumor immunity in the microenvironment $(28,97-102)$. For instance, the ILC2/IL-13/MDSC axis has been demonstrated to contribute to the formation of the immunosuppressive microenvironment in a wide range of cancer types, including acute promyelocytic leukemia, as well as gastric, prostate and bladder cancer (which have been discussed above in this article). IL-22 and IL-17, which are secreted by ILC3s, may promote tumor proliferation and prevent tumor cell apoptosis, whereas Itch, an E3 ubiquitin ligase, has been indicated to inhibit IL-17-mediated tumorigenesis through inducing ROR- $\gamma$ t ubiquitination (103). However, there are also anti-tumor effects associated with these ILCs; in addition to what has been discussed above in this article, Kim et al (104) demonstrated that IL-33-induced activation of ILC2s promoted a vast secretion of CXCL2, 
which, when combined with CXCR2 expression in tumor cells following dysfunction of the angiogenesis/hypoxia/reactive oxygen species axis, resulted in apoptosis of tumor cells. All of these ILC-associated pathways may serve as potential therapeutic targets for immunotherapy treatments for cancer. Furthermore, it is worth mentioning that certain biological signals, which actively regulate the plasticity of ILCs, such as TGF- $\beta$ that converts NK cells into helper ILC1s, may be employed in future therapeutic strategies as well $(79,81)$.

In addition, numerous studies focusing on the activities of ILCs in patients undergoing allogeneic haematopoietic stem cell transplantation (HSCT), the primary treatment option for hematological malignancies, observed that activated $\mathrm{NCR}^{+}$ ILC3s and ILC2s made patients less sensitive to GVHD and protected tissues against GVHD-inflicted damage $(54,99)$. These studies suggested that in vitro, it may be possible to expand $\mathrm{NCR}^{+}$ILC3 and ILC2 populations to protect against GVHD in patients undergoing allogeneic HSCT, which may therefore render HSCT a more reliable treatment for hematologic malignancies.

\section{Conclusions}

With the significant advances in this field, the definitions and current knowledge of ILC subpopulations are becoming increasingly clear, and the roles of ILCs as important mediators in multiple diseases have been revealed. However, to date, studies on ILCs have mainly focused on their roles in immunity-associated and inflammatory diseases, such as IBD, psoriasis and dermatitis, and primarily at the cellular level or using mouse model systems, with only a small proportion of studies focusing on human cancers.

Based on the basic current understanding, ILCs either facilitate tumor surveillance or have tumor-promoting functions in the microenvironment, which may depend on the specificity of tumors, stimulation of signals in the tumor microenvironment, the proportion and dysregulation of ILCs, as well as the different secreted factors they produce. Given the intricate but crucial roles of ILCs, there is an urgent requirement to investigate therapeutic strategies in which the number of ILCs and their subsequent activation and downstream pathways, may be shifted towards entirely protective effects, which may be clinically useful for the treatment of cancer. Thus, further investigations into tumor-associated ILCs are required to elucidate the roles of ILCs in human cancers and to determine whether these cells may indeed be manipulated, and if so, how to utilize them effectively.

\section{Acknowledgements}

Not applicable.

\section{Funding}

No funding was received.

\section{Availability of data and materials}

Not applicable.

\section{Authors' contributions}

SW and YC were major contributors in conceiving the review and analyzing the relevant literature. PW and YYC wrote, edited and reviewed a part of the manuscript. All authors read and approved the final manuscript.

\section{Ethics approval and consent to participate}

Not applicable.

\section{Patient consent for publication}

Not applicable.

\section{Competing interests}

The authors declare that they have no competing interests.

\section{References}

1. Withers DR: Innate lymphoid cell regulation of adaptive immunity. Immunology 149: 123-130, 2016.

2. Iwasaki A and Medzhitov R: Regulation of adaptive immunity by the innate immune system. Science 327: 291-295, 2010.

3. Eberl G, Colonna M, Di Santo JP and McKenzie AN: Innate lymphoid cells. Innate lymphoid cells: A new paradigm in immunology. Science 348: aaa6566, 2015.

4. Ebbo M, Crinier A, Vély F and Vivier E: Innate lymphoid cells: Major players in inflammatory diseases. Nat Rev Immunol 17: 665-678, 2017.

5. Kumar V: Innate lymphoid cells: New paradigm in immunology of inflammation. Immunol Lett 157: 23-37, 2014.

6. Artis D and Spits H: The biology of innate lymphoid cells. Nature 517: 293-301, 2015.

7. Spits $\mathrm{H}$ and Cupedo T: Innate lymphoid cells: Emerging insights in development, lineage relationships, and function. Annu Rev Immunol 30: 647-675, 2012.

8. Kiessling R, Klein E, Pross H and Wigzell H: 'Natural' killer cells in the mouse. II. Cytotoxic cells with specificity for mouse Moloney leukemia cells. Characteristics of the killer cell. Eur J Immunol 5: 117-121, 1975.

9. Kiessling R, Klein E and Wigzell H: 'Natural' killer cells in the mouse. I. Cytotoxic cells with specificity for mouse Moloney leukemia cells. Specificity and distribution according to genotype. Eur J Immunol 5: 112-117, 1975.

10. Mebius RE, Rennert P and Weissman IL: Developing lymph nodes collect CD4+CD3- LTbeta+ cells that can differentiate to APC, NK cells, and follicular cells but not T or B cells. Immunity 7: 493-504, 1997.

11. Cella M, Fuchs A, Vermi W, Facchetti F, Otero K, Lennerz JK, Doherty JM, Mills JC and Colonna M: A human natural killer cell subset provides an innate source of IL-22 for mucosal immunity. Nature 457: 722-725, 2009.

12. Moro K, Yamada T, Tanabe M, Takeuchi T, Ikawa T, Kawamoto H, Furusawa J, Ohtani M, Fujii H and Koyasu S: Innate production of $\mathrm{T}(\mathrm{H}) 2$ cytokines by adipose tissue-associated c-Kit(+)Sca-1(+) lymphoid cells. Nature 463: 540-544, 2010.

13. Neill DR, Wong SH, Bellosi A, Flynn RJ, Daly M, Langford TK, Bucks C, Kane CM, Fallon PG, Pannell R, et al: Nuocytes represent a new innate effector leukocyte that mediates type-2 immunity. Nature 464: 1367-1370, 2010.

14. Saglani S: Innate helper cells: A novel cell type essential in the initiation of asthma? Thorax 66: 834-835, 2011.

15. Saenz SA, Siracusa MC, Perrigoue JG, Spencer SP, Urban JF Jr, Tocker JE, Budelsky AL, Kleinschek MA, Kastelein RA, Kambayashi T, et al: IL25 elicits a multipotent progenitor cell population that promotes $\mathrm{T}(\mathrm{H}) 2$ cytokine responses. Nature 464 : 1362-1366, 2010.

16. Koyasu S, Moro K, Tanabe $M$ and Takeuchi T: Natural helper cells: A new player in the innate immune response against helminth infection. Adv Immunol 108: 21-44, 2010. 
17. Fuchs A, Vermi W, Lee JS, Lonardi S, Gilfillan S, Newberry RD, Cella $\mathrm{M}$ and Colonna $\mathrm{M}$ : Intraepithelial type 1 innate lymphoid cells are a unique subset of IL-12- and IL-15-responsive IFN- $\gamma$-producing cells. Immunity 38: 769-781, 2013.

18. Spits H, Artis D, Colonna M, Diefenbach A, Di Santo JP, Eberl G, Koyasu S, Locksley RM, McKenzie AN, Mebius RE, et al: Innate lymphoid cells-a proposal for uniform nomenclature. Nat Rev Immunol 13: 145-149, 2013

19. Vivier E, Artis D, Colonna M, Diefenbach A, Di Santo JP, Eberl G, Koyasu S, Locksley RM, McKenzie ANJ, Mebius RE, et al: Innate lymphoid cells: 10 years on. Cell 174: 1054-1066, 2018

20. Morvan MG and Lanier LL: NK cells and cancer: You can teach innate cells new tricks. Nat Rev Cancer 16: 7-19, 2016.

21. Guillerey $C$ and Smyth MJ: NK cells and cancer immunoediting. Curr Top Microbiol Immunol 395: 115-145, 2016.

22. Klose CS and Artis D: Innate lymphoid cells as regulators of immunity, inflammation and tissue homeostasis. Nat Immunol 17: 765-774, 2016.

23. Simoni Y, Fehlings M, Kløverpris HN, McGovern N, Koo SL Loh CY, Lim S, Kurioka A, Fergusson JR, Tang CL, et al: Human innate lymphoid cell subsets possess tissue-type based heterogeneity in phenotype and frequency. Immunity 46: 148-161, 2017.

24. Spits H, Bernink JH and Lanier L: NK cells and type 1 innate lymphoid cells: Partners in host defense. Nat Immunol 17 : 758-764, 2016.

25. Bernink JH, Peters CP, Munneke M, te Velde AA, Meijer SL, Weijer K, Hreggvidsdottir HS, Heinsbroek SE, Legrand N, Buskens CJ, et al: Human type 1 innate lymphoid cells accumulate in inflamed mucosal tissues. Nat Immunol 14: 221-229, 2013.

26. Monticelli LA, Sonnenberg GF, Abt MC, Alenghat T, Ziegler CG, Doering TA, Angelosanto JM, Laidlaw BJ, Yang CY, Sathaliyawala T, et al: Innate lymphoid cells promote lung-tissue homeostasis after infection with influenza virus. Nat Immunol 12: 1045-1054, 2011.

27. Gieseck RL III, Wilson MS and Wynn TA: Type 2 immunity in tissue repair and fibrosis. Science 18: 62-76, 2018.

28. Goc J, Hepworth MR and Sonnenberg GF: Group 3 innate lymphoid cells: Regulating host-commensal bacteria interactions in inflammation and cancer. Int Immunol 28: 43-52, 2016

29. Zheng Y, Valdez PA, Danilenko DM, Hu Y, Sa SM, Gong Q Abbas AR, Modrusan Z, Ghilardi N, de Sauvage FJ and Ouyang W: Interleukin-22 mediates early host defense against attaching and effacing bacterial pathogens. Nat Med 14: 282-289, 2008.

30. Klose CS, Kiss EA, Schwierzeck V, Ebert K, Hoyler T, d'Hargues Y, Göppert N, Croxford AL, Waisman A, Tanriver Y and Diefenbach A: A T-bet gradient controls the fate and function of CCR6-ROR $\gamma t+$ innate lymphoid cells. Nature 494: 261-265, 2013.

31. Buonocore S, Ahern PP, Uhlig HH, Ivanov II, Littman DR, Maloy KJ and Powrie F: Innate lymphoid cells drive interleukin-23-dependent innate intestinal pathology. Nature 464: $1371-1375,2010$

32. Kim HY, Lee HJ, Chang YJ, Pichavant M, Shore SA, Fitzgerald KA, Iwakura Y, Israel E, Bolger K, Faul J, et al: Interleukin-17-producing innate lymphoid cells and the NLRP3 inflammasome facilitate obesity-associated airway hyperreactivity. Nat Med 20: 54-61, 2014.

33. Scandella E, Bolinger B, Lattmann E, Miller S, Favre S, Littman DR, Finke D, Luther SA, Junt T and Ludewig B: Restoration of lymphoid organ integrity through the interaction of lymphoid tissue-inducer cells with stroma of the T cell zone. Nat Immunol 9: 667-675, 2008.

34. Singh N, Baby D, Rajguru JP, Patil PB, Thakkannavar SS and Pujari VB: Inflammation and cancer. Ann Afr Med 18: 121-126, 2019.

35. Balkwill $\mathrm{F}$ and Mantovani A: Inflammation and cancer: Back to Virchow? Lancet 357: 539-545, 2001.

36. Yang S, Tian Z, Wu Y, van Velkinburgh JC and Ni B: Pivotal roles of ILCs in hepatic diseases. Int Rev Immunol 34: 509-522, 2015.

37. Sun C, Sun H, Zhang C and Tian Z: NK cell receptor imbalance and NK cell dysfunction in HBV infection and hepatocellular carcinoma. Cell Mol Immunol 12: 292-302, 2015.

38. Han X, Huang T and Han J: Cytokines derived from innate lymphoid cells assist Helicobacter hepaticus to aggravate hepatocellular tumorigenesis in viral transgenic mice. Gut Pathog 11: $23,2019$.
39. McHedlidze T, Waldner M, Zopf S, Walker J, Rankin AL, Schuchmann M, Voehringer D, McKenzie AN, Neurath MF, Pflanz S and Wirtz S: Interleukin-33-dependent innate lymphoid cells mediate hepatic fibrosis. Immunity 39: 357-371, 2013.

40. Li J, Razumilava N, Gores GJ, Walters S, Mizuochi T, Mourya R, Bessho K, Wang YH, Glaser SS, Shivakumar P and Bezerra JA: Biliary repair and carcinogenesis are mediated by IL-33-dependent cholangiocyte proliferation. J Clin Invest 124: 3241-3251, 2014

41. Jiang R, Tan Z, Deng L, Chen Y, Xia Y, Gao Y, Wang X and Sun B: Interleukin-22 promotes human hepatocellular carcinoma by activation of STAT3. Hepatology 54: 900-909, 2011.

42. Geremia A, Arancibia-Cárcamo CV, Fleming MP, Rust N, Singh B, Mortensen NJ, Travis SP and Powrie F: IL-23-responsive innate lymphoid cells are increased in inflammatory bowel disease. J Exp Med 208: 1127-1133, 2011.

43. Fuchs A and Colonna M: Innate lymphoid cells in homeostasis, infection, chronic inflammation and tumors of the gastrointestinal tract. Curr Opin Gastroenterol 29: 581-587, 2013.

44. Castleman MJ, Dillon SM, Purba CM, Cogswell AC, Kibbie JJ, McCarter MD, Santiago ML, Barker E and Wilson CC: Commensal and pathogenic bacteria indirectly induce IL-22 but Not IFN $\gamma$ production from human colonic ILC3s via multiple mechanisms. Front Immunol 10: 649, 2019.

45. Man SM: Inflammasomes in the gastrointestinal tract: Infection, cancer and gut microbiota homeostasis. Nat Rev Gastroenterol Hepatol 15: 721-737, 2018

46. Chan IH, Jain R, Tessmer MS, Gorman D, Mangadu R, Sathe M, Vives F, Moon C, Penaflor E, Turner S, et al: Interleukin-23 is sufficient to induce rapid de novo gut tumorigenesis, independent of carcinogens, through activation of innate lymphoid cells. Mucosal Immunol 7: 842-856, 2014

47. Kirchberger S, Royston DJ, Boulard O, Thornton E, Franchini F, Szabady RL, Harrison O and Powrie F: Innate lymphoid cells sustain colon cancer through production of interleukin-22 in a mouse model. J Exp Med 210: 917-931, 2013.

48. Bergmann H, Roth S, Pechloff K, Kiss EA, Kuhn S, Heikenwälder M, Diefenbach A, Greten FR and Ruland J: Card9-dependent IL-1 $\beta$ regulates IL-22 production from group 3 innate lymphoid cells and promotes colitis-associated cancer. Eur J Immunol 47: 1342-1353, 2017.

49. Saadalla AM, Osman A, Gurish MF, Dennis KL, Blatner NR, Pezeshki A, McNagny KM, Cheroutre H, Gounari F and Khazaie K: Mast cells promote small bowel cancer in a tumor stage-specific and cytokine-dependent manner. Proc Natl Acad Sci USA 115: 1588-1592, 2018.

50. Chang WJ, Du Y, Zhao X, Ma LY and Cao GW: Inflammationrelated factors predicting prognosis of gastric cancer. World $\mathbf{J}$ Gastroenterol 20: 4586-4596, 2014.

51. Bie Q, Zhang P, Su Z, Zheng D, Ying X, Wu Y, Yang H, Chen D, Wang $\mathrm{S}$ and $\mathrm{Xu} \mathrm{H}$ : Polarization of ILC2s in peripheral blood might contribute to immunosuppressive microenvironment in patients with gastric cancer. J Immunol Res 2014: 923135 , 2014.

52. Salimi M, Wang R, Yao X, Li X, Wang X, Hu Y, Chang X, Fan P, Dong $\mathrm{T}$ and Ogg G: Activated innate lymphoid cell populations accumulate in human tumour tissues. BMC Cancer 18: 341, 2018.

53. Trabanelli S, Curti A, Lecciso M, Salomé B, Riether C, Ochsenbein A, Romero P and Jandus C: CD127+ innate lymphoid cells are dysregulated in treatment naïve acute myeloid leukemia patients at diagnosis. Haematologica 100: e257-e260, 2015.

54. Munneke JM, Björklund AT, Mjösberg JM, Garming-Legert K, Bernink JH, Blom B, Huisman C, van Oers MH, Spits H, Malmberg KJ and Hazenberg MD: Activated innate lymphoid cells are associated with a reduced susceptibility to graft-versus-host disease. Blood 124: 812-821, 2014.

55. Trabanelli S, Chevalier MF, Martinez-Usatorre A, GomezCadena A, Salomé B, Lecciso M, Salvestrini V, Verdeil G, Racle J, Papayannidis C, et al: Tumour-derived PGD2 and NKp30-B7H6 engagement drives an immunosuppressive ILC2-MDSC axis. Nat Commun 8: 593, 2017.

56. de Weerdt I, van Hoeven V, Munneke JM, Endstra S, Hofland T, Hazenberg MD and Kater AP: Innate lymphoid cells are expanded and functionally altered in chronic lymphocytic leukemia. Haematologica 101: e461-e464, 2016.

57. Schleussner N, Merkel O, Costanza M, Liang HC, Hummel F, Romagnani C, Durek P, Anagnostopoulos I, Hummel M, Jöhrens K, et al: The AP-1-BATF and -BATF3 module is essential for growth, survival and TH17/ILC3 skewing of anaplastic large cell lymphoma. Leukemia 32: 1994-2007, 2018. 
58. Harbeck N and Gnant M: Breast cancer. Lancet 389: 1134-1150, 2017.

59. Stein JV and Nombela-Arrieta C: Chemokine control of lymphocyte trafficking: A general overview. Immunology 116: 1-12, 2005.

60. Jovanovic IP, Pejnovic NN, Radosavljevic GD, Pantic JM, Milovanovic MZ, Arsenijevic NN and Lukic ML: Interleukin-33/ST2 axis promotes breast cancer growth and metastases by facilitating intratumoral accumulation of immunosuppressive and innate lymphoid cells. Int J Cancer 134: 1669-1682, 2014

61. Irshad S, Flores-Borja F, Lawler K, Monypenny J, Evans R, Male V, Gordon P, Cheung A, Gazinska P, Noor F, et al: ROR $\gamma \mathrm{t}+$ innate lymphoid cells promote lymph node metastasis of breast cancers. Cancer Res 77: 1083-1096, 2017.

62. Carrega P, Loiacono F, Di Carlo E, Scaramuccia A, Mora M, Conte R, Benelli R, Spaggiari GM, Cantoni C, Campana S, et al: NCR(+)ILC3 concentrate in human lung cancer and associate with intratumoral lymphoid structures. Nat Commun 6: 8280, 2015.

63. Koh J, Kim HY, Lee Y, Park IK, Kang CH, Kim YT, Kim JE, Choi M, Lee WW, Jeon YK and Chung DH: IL23-producing human lung cancer cells promote tumor growth via conversion of innate lymphoid cell 1 (ILC1) into ILC3. Clin Cancer Res 25: 4026-4037, 2019.

64. Wu Y, Yan Y, Su Z, Bie Q, Chen X, Barnie PA, Guo Q, Wang $\mathrm{S}$ and $\mathrm{Xu} \mathrm{H}$ : Enhanced circulating ILC2s and MDSCs may contribute to ensure maintenance of Th2 predominant in patients with lung cancer. Mol Med Rep 15: 4374-4381, 2017.

65. Cui W, Zhang W, Yuan X, Liu S, Li M, Niu J, Zhang P and Li D: Vitamin A deficiency execrates Lewis lung carcinoma via induction of type 2 innate lymphoid cells and alternatively activates macrophages. Food Sci Nutr 7: 1288-1294, 2019.

66. Bruchard $\mathrm{M}$ and Ghiringhelli F: Deciphering the roles of innate lymphoid cells in cancer. Front Immunol 10: 656, 2019.

67. Eisenring M, vom Berg J, Kristiansen G, Saller E and Becher B: IL-12 initiates tumor rejection via lymphoid tissue-inducer cells bearing the natural cytotoxicity receptor NKp46. Nat Immunol 11: 1030-1038, 2010.

68. Lotfi R, Lee JJ and Lotze MT: Eosinophilic granulocytes and damage-associated molecular pattern molecules (DAMPs): Role in the inflammatory response within tumors. J Immunother 30 16-28, 2007.

69. Ikutani M, Yanagibashi $\mathrm{T}$, Ogasawara M, Tsuneyama $\mathrm{K}$, Yamamoto S, Hattori Y, Kouro T, Itakura A, Nagai Y, Takaki S and Takatsu K: Identification of innate IL-5-producing cells and their role in lung eosinophil regulation and antitumor immunity. J Immunol 188: 703-713, 2012

70. Moskalenko M, Pan M, Fu Y, de Moll EH, Hashimoto D Mortha A, Leboeuf M, Jayaraman P, Bernardo S, Sikora AG, et al: Requirement for innate immunity and CD90+ NK1.1' lymphocytes to treat established melanoma with chemo-immunotherapy. Cancer Immunol Res 3: 296-304, 2015.

71. Shields JD, Kourtis IC, Tomei AA, Roberts JM and Swartz MA Induction of lymphoidlike stroma and immune escape by tumors that express the chemokine CCL21. Science 328: 749-752, 2010

72. Chevalier MF, Trabanelli S, Racle J, Salomé B, Cesson V, Gharbi D, Bohner P, Domingos-Pereira S, Dartiguenave F, Fritschi AS, et al: ILC2-modulated T cell-to-MDSC balance is associated with bladder cancer recurrence. J Clin Invest 127: 2916-2929, 2017.

73. Crome SQ, Nguyen LT, Lopez-Verges S, Yang SY, Martin B, Yam JY, Johnson DJ, Nie J, Pniak M, Yen PH, et al: A distinct innate lymphoid cell population regulates tumor-associated T cells. Nat Med 23: 368-375, 2017.

74. Punt S, Fleuren GJ, Kritikou E, Lubberts E, Trimbos JB, Jordanova ES and Gorter A: Angels and demons: Th17 cells represent a beneficial response, while neutrophil IL-17 is associated with poor prognosis in squamous cervical cancer. Oncoimmunology 4: e984539, 2015.

75. Bonelli M, Shih HY, Hirahara K, Singelton K, Laurence A, Poholek A, Hand T, Mikami Y, Vahedi G, Kanno Y and O'Shea JJ: Helper T cell plasticity: Impact of extrinsic and intrinsic signals on transcriptomes and epigenomes. Curr Top Microbiol Immunol 381: 279-326, 2014.

76. Gaffen SL, Jain R, Garg AV and Cua DJ: The IL-23-IL-17 immune axis: From mechanisms to therapeutic testing. Nat Rev Immunol 14: 585-600, 2014.
77. Mucida D, Husain MM, Muroi S, van Wijk F, Shinnakasu R, Naoe Y, Reis BS, Huang Y, Lambolez F, Docherty M, et al: Transcriptional reprogramming of mature CD4+ helper T cells generates distinct MHC class II-restricted cytotoxic T lymphocytes. Nat Immunol 14: 281-289, 2013

78. Gao Y, Souza-Fonseca-Guimaraes F, Bald T, Ng SS, Young A, Ngiow SF, Rautela J, Straube J, Waddell N, Blake SJ, et al: Tumor immunoevasion by the conversion of effector NK cells into type 1 innate lymphoid cells. Nat Immunol 18: 1004-1015, 2017.

79. Cortez VS, Ulland TK, Cervantes-Barragan L, Bando JK, Robinette ML, Wang Q, White AJ, Gilfillan S, Cella M and Colonna M: SMAD4 impedes the conversion of NK cells into ILC1-like cells by curtailing non-canonical TGF- $\beta$ signaling. Nat Immunol 18: 995-1003, 2017

80. Chea S, Perchet T, Petit M, Verrier T, Guy-Grand D, Banchi EG Vosshenrich CA, Di Santo JP, Cumano A and Golub R: Notch signaling in group 3 innate lymphoid cells modulates their plasticity. Sci Signal 9: ra45, 2016.

81. Viant C, Rankin LC, Girard-Madoux MJ, Seillet C, Shi W, Smyth MJ, Bartholin L, Walzer T, Huntington ND, Vivier E and Belz GT: Transforming growth factor- $\beta$ and Notch ligands act as opposing environmental cues in regulating the plasticity of type 3 innate lymphoid cells. Sci Signal 9: ra46, 2016.

82. Bal SM, Bernink JH, Nagasawa M, Groot J, Shikhagaie MM, Golebski K, van Drunen CM, Lutter R, Jonkers RE, Hombrink P, et al: IL-1 $\beta$, IL-4 and IL-12 control the fate of group 2 innate lymphoid cells in human airway inflammation in the lungs. Nat Immunol 17: 636-645, 2016.

83. Lim AI, Menegatti S, Bustamante J, Le Bourhis L, Allez M, Rogge L, Casanova JL, Yssel H and Di Santo JP: IL-12 drives functional plasticity of human group 2 innate lymphoid cells. J Exp Med 213: 569-583, 2016.

84. Ohne Y, Silver JS, Thompson-Snipes L, Collet MA, Blanck JP, Cantarel BL, Copenhaver AM, Humbles AA and Liu YJ: IL-1 is a critical regulator of group 2 innate lymphoid cell function and plasticity. Nat Immunol 17: 646-655, 2016.

85. Silver JS, Kearley J, Copenhaver AM, Sanden C, Mori M, Yu L, Pritchard GH, Berlin AA, Hunter CA, Bowler R, et al: Inflammatory triggers associated with exacerbations of COPD orchestrate plasticity of group 2 innate lymphoid cells in the lungs. Nat Immunol 17: 626-635, 2016.

86. Bernink JH, Krabbendam L, Germar K, de Jong E, Gronke K, Kofoed-Nielsen M, Munneke JM, Hazenberg MD, Villaudy J, Buskens CJ, et al: Interleukin-12 and -23 control plasticity of CD127(+) group 1 and group 3 innate lymphoid cells in the intestinal lamina propria. Immunity 43: 146-160, 2015.

87. Crellin NK, Trifari S, Kaplan CD, Satoh-Takayama N, Di Santo JP and Spits H: Regulation of cytokine secretion in human CD127(+) LTi-like innate lymphoid cells by Toll-like receptor 2. Immunity 33: 752-764, 2010.

88. Huang Y, Guo L, Qiu J, Chen X, Hu-Li J, Siebenlist U, Williamson PR, Urban JF Jr and Paul WE: IL-25-responsive, lineage-negative KLRG1(hi) cells are multipotential 'inflammatory' type 2 innate lymphoid cells. Nat Immunol 16: 161-169, 2015

89. Pietra G, Vitale C, Pende D, Bertaina A, Moretta F, Falco M, Vacca P, Montaldo E, Cantoni C, Mingari MC, et al: Human natural killer cells: News in the therapy of solid tumors and high-risk leukemias. Cancer Immunol Immunother 65: 465-476, 2016.

90. Baumeister SH, Freeman GJ, Dranoff $G$ and Sharpe AH: Coinhibitory pathways in immunotherapy for cancer. Annu Rev Immunol 34: 539-573, 2016.

91. Khalil DN, Smith EL, Brentjens RJ and Wolchok JD: The future of cancer treatment: Immunomodulation, CARs and combination immunotherapy. Nat Rev Clin Oncol 13: 273-290, 2016.

92. Ribas A and Wolchok JD: Cancer immunotherapy using checkpoint blockade. Science 359: 1350-1355, 2018.

93. Mallett G, Laurence A and Amarnath S: Programmed cell death-1 receptor (PD-1)-mediated regulation of innate lymphoid cells. Int J Mol Sci 20: pii: E2836, 2019.

94. Tumino N, Martini S, Munari E, Tumino N, Martini S, Munari E, Scordamaglia F, Besi F, Mariotti FR, Bogina G, et al: Presence of innate lymphoid cells in pleural effusions of primary and metastatic tumors: Functional analysis and expression of PD-1 receptor. Int J Cancer 145: 1660-1668, 2019.

95. Wang T, Zheng N, Luo Q, Jiang L, He B, Yuan X and Shen L: Probiotics lactobacillus reuteri abrogates immune checkpoint blockade-associated colitis by inhibiting group 3 innate lymphoid cells. Front Immunol 10: 1235, 2019. 
96. Turchinovich G, Ganter S, Bärenwaldt A and Finke D: NKp46 Calibrates tumoricidal potential of type 1 innate lymphocytes by regulating TRAIL expression. J Immunol 200: 3762-3768, 2018.

97. Zaiss DMW, Gause WC, Osborne LC and Artis D: Emerging functions of amphiregulin in orchestrating immunity, inflammation, and tissue repair. Immunity 42: 216-226, 2015.

98. Lu B, Yang M and Wang Q: Interleukin-33 in tumorigenesis, tumor immune evasion, and cancer immunotherapy. J Mol Med (Berl) 94: 535-543, 2016.

99. Hanash AM, Dudakov JA, Hua G, O'Connor MH, Young LF, Singer NV, West ML, Jenq RR, Holland AM, Kappel LW, et al: Interleukin-22 protects intestinal stem cells from immune-mediated tissue damage and regulates sensitivity to graft versus host disease. Immunity 37: 339-350, 2012

100. Lim C and Savan R: The role of the IL-22/IL-22R1 axis in cancer. Cytokine Growth Factor Rev 25: 257-271, 2014.
101. Markota A, Endres S and Kobold S: Targeting interleukin-22 for cancer therapy. Hum Vaccin Immunother 14: 2012-2015, 2018.

102. Song Y and Yang JM: Role of interleukin (IL)-17 and T-helper (Th) 17 cells in cancer. $\mathrm{s}$ 493: 1-8, 2017.

103. Kathania M, Khare P, Zeng M, Cantarel B, Zhang H, Ueno H and Venuprasad K: Itch inhibits IL-17-mediated colon inflammation and tumorigenesis by ROR- $\gamma$ t ubiquitination. Nat Immunol 17: 997-1004, 2016

104. Kim J, Kim W, Moon UJ, Kim HJ, Choi HJ, Sin JI, Park NH, Cho HR and Kwon B: Intratumorally establishing type 2 innate lymphoid cells blocks tumor growth. J Immunol 196: 2410-2423, 2016.

This work is licensed under a Creative Commons Attribution-NonCommercial-NoDerivatives 4.0 International (CC BY-NC-ND 4.0) License. 